$3 / 8$-inch in diameter and 16 inches long. This rod is securely held in a perpendicular position in front of the motor by two brass bearings; the lower or end bearing is simply a brass block with a $3 / 8$-ineh hole drilled part way through the center and is screwed to the board on which the motor rests. A $3 / 8$-inch ball bearing is dropped in the hole in the bearing, and the lower end of the steel rod is slightly concaved so that it will rotate smoothly. The upper bearing is a brass cylinder one inch in

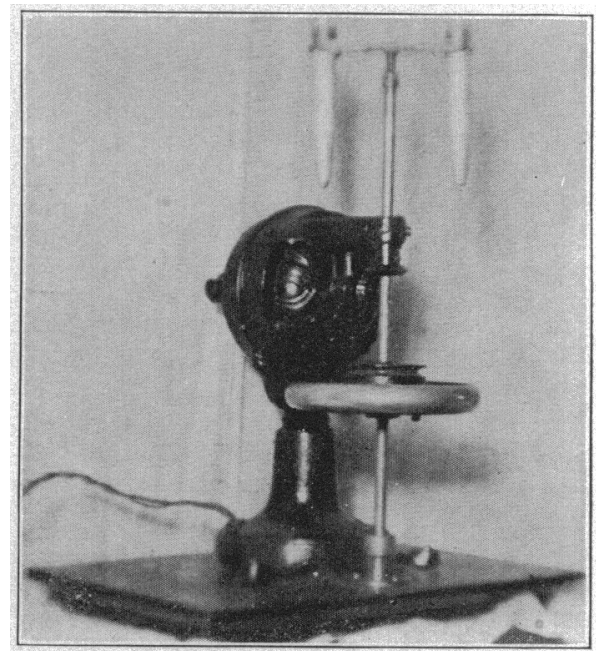

A home-made electric centrifuge.

diameter and an inch or more long, with a $3 / 8$-inch hole through its center. This bearing is held in place by a V-shaped brace, made of a strip of jron $1 / 32$-inch thick and about an inch wide, the apex of the $\mathrm{V}$ being rounded to fit around the bearing; this brace is fastened to the motor frame by two screws, one at each end of the $\mathrm{V}$ (the screws which attach the fan guard may be used for this purpose), and the bearing is fastened in the rounded apex of the brace with two small screws.

A sewing-machine balance wheel is attached to the upright rod between the two bearings and the arm carrying the sedimentation tubes is attached to the top of the rod. The arm and tubes of a hand centrifuge may be used. To eliminate vibration it is necessary to have the balance wheel centered perfectly on the rod and to have the bearings neatly fitted, and the bevel gears not meshed too closely. The bearings should be oiled frequently.

The entire cost of labor and material in thus converting my fan into a centrifuge was $\$ 3.50$.

No doubt many physicians have electric fans in their offices which stand idle except for a few weeks in summer and could be profitably used the remainder of the year as centrifuges.

1405 Tenth Street.

Breast-Feeding of Infants.-Those who stop to think will realize that even partial breast-feeding favors an undisturbed digestion in the infant and a safer and more continuous development. Yet many a mother whose milk could readily be made to assist in the eariy nutrition of her infant is ignorantly sdvised or allowed to discard it for the greater uncertainties of total bottle-feeding.-T. S. Southworth, in 4m. Jour. Obst. and Dis. Women and Children.

\section{SYPHILIS IN CHILDREN}

MY EXPERIENCE WITII SALVARSAN : IMMEDIATE RESULTS AND LATER TOXIC MANIFESTATIONS

\section{LOUIS FISCHER, M.D.}

Attending Physician to the Children's Wards of the Sydenham IIospital, and Attending Physician to the Willard Parker and Riverside Hospitals NEW YORK

In order to study the true value of salvarsan, I have selected three common types of syphilitic lesions most usually encountered in children.

1. A boy having syphilitic lesions in knee-joint, with infiltration, swelling, and pain on extension or flexion of joint. He was castrated for gumma of left testicle, several years ago.

2. A child with congenital syphilis liaving lesions (a gumma and condylomata) on vulva, around the anus. This patient was photographed before and one week after treatment, to illustrate the apparent benefit.

3. A girl with congenital syphilis, showing all evidence of malnutrition, having an enormous spleen palpable two fingers below the umbilicus, swollen glands in various parts of the body, a very large liver and icterus.

No patient was subjected to this treatment until a positive Wassermann and a positive Noguchi reaction were obtained. It was not easy, in Case 1, to demonstrate the spirochetes, although diligent search was made for them by Dr. Fred. Sondern.

In Case 2 , the spirochata refringens, not the pallida, was found. For all Wassermann and Noguchi examinations, I am indebted to the courtesy of Dr. D. M. Kaplan, Director of the Laboratory of the Neurological Institute.

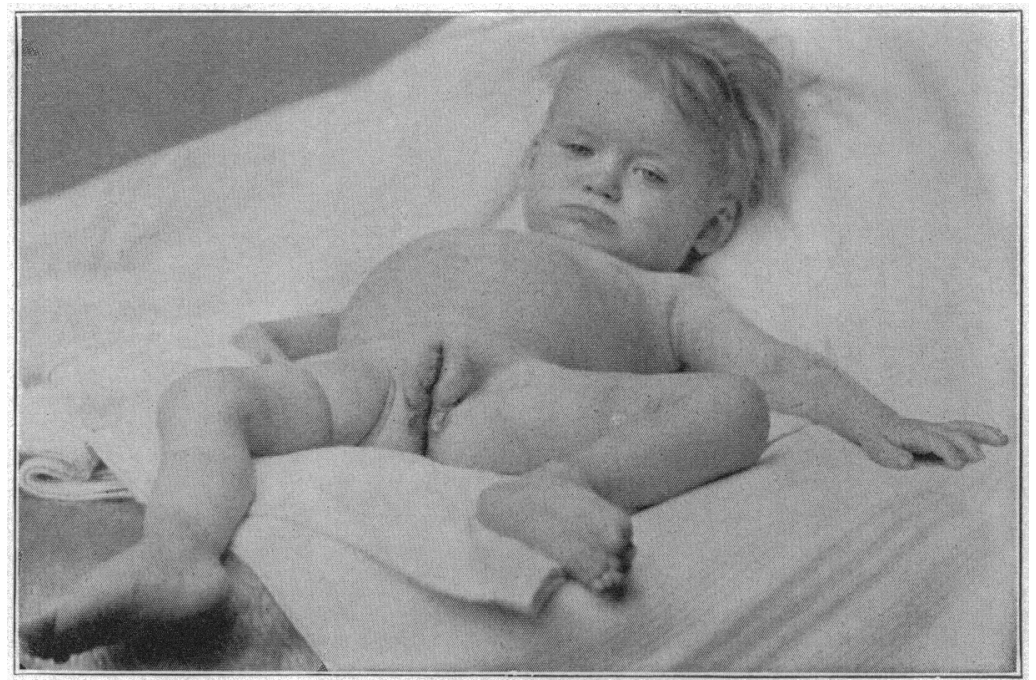

Fig. 1.-Margaret $K$, 18 months old, with congenital syphilis, before injection of salvarsan.
'The blood was examined before and after the injection, and showed a slight increase in the polymorphonuclear leukocytes, also a slightly increasing leukocytosis.

In one case, in addition to a positive Wassermann, a positive cutaneous tuberculin reaction (Von Pirquet), by inoculating human tuberculin, was found, showing a notable though frequent association of tuberculosis with syphilis.

Clinical details were carefully studied by Dr. M. I reund, house physician of hospital, to whom I am indebted for painstaking supervision, in addition to 
Dr. Heller, for additional clinical notes. The blood examinations were made by Dr. Gunzburg of the resident house staff.

The immediate result in all cases seen by me was a marked improvement. By improvement is meant the effect on visible gummata and condylomata. There was a general brightening up, and to all appearances a sudden change had taken place. In one case which I report the joint swelling improved rapidly, and the child was discharged greatly benefited after fourteen days treatment at the hospital. One injection was given, and no after-treatment. The patient reported to me weekly; and six weeks after the improvement above mentioned, I note an apparent change for the better.

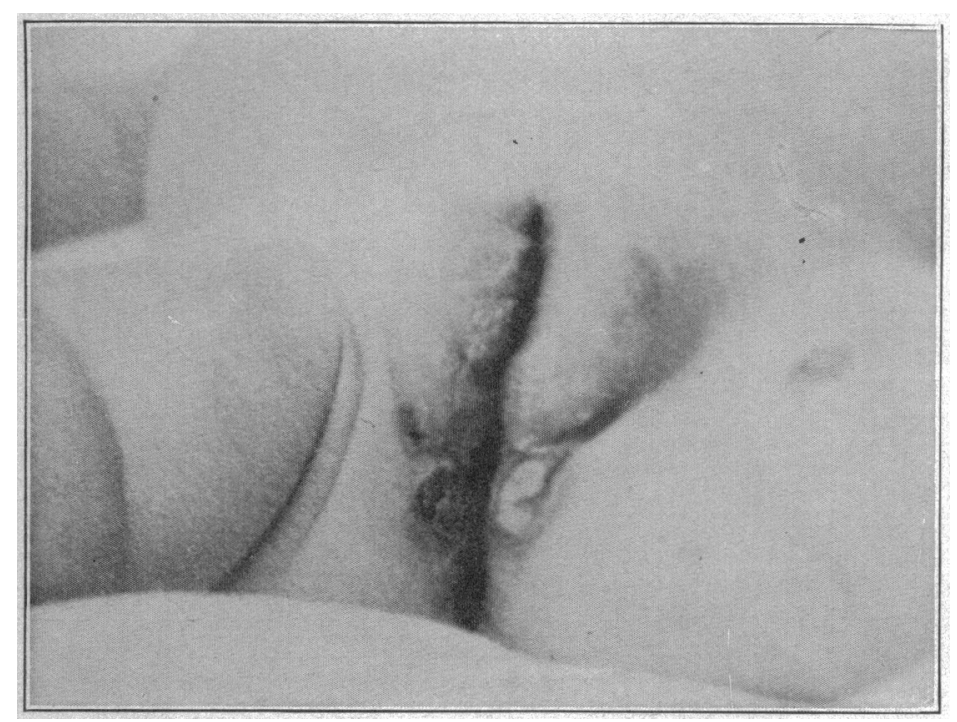

On admission to hospital a diagnosis of gumma on the vulva, and condylomata on the vulva and anus was made. Wassermann reaction was positive, also the Noguchi. A smear taken from the surface of gumma was carefully examined by $\mathrm{Dr}$. Fred. Sondern, who reported the presence of Spirochata refrin. gens but not the Spirochota pallida.

The diagnosis being positive, an injection of $0.3 \mathrm{gm}$. salvarsan was given in the left buttock. Within twenty-four hours the swelling of the vulva and the gumma began to melt away, the swelling of other parts decreased and marked benefit followed.

A severe local infiltration followed with marked febrile reaction and swelling which subsided by local antiphlogistic treatment. It is almost impossible to credit sufficiently the immediate benefit noticed in the lesions, by those who saw the pase from day to day.

This condition of improvement was suddenly changed to one of visible loss of power. This was more marked on the left side. At the site of injection, an induration was palpable and from a slight fistulous opening we expressed a yellowish-green mass resembling unabsorbed concentrated Ehrlich-Hata preparation. In addition thereto yellowish coagula resembling necrotic tissue was expressed. There was no Herxheimer ${ }^{1}$ reaction present.

Toxic Manifestations.-In this case the visible lesions covering the vulva and labia disappeared and did not return. The muscles of the legs suddenly lost their tone; they were limp and flaccid. Marked trophic changes were noted as early as two weeks after the injection. On the left side the plantar reflex was absent and the patellar reflex was lost. There was progressive atrophy of the extensor and flexor group of muscles of the thigh, calf and leg. The infant seemed to have lost all strength. The sphincters of the bladder and rectum functioned properly. There was a slight drop-foot.

On the right side we had trophic changes involving the thigh and leg. There was also a soft flaceid condition of the inusiles and progressive emaciation. The

Fig. 2.-Appearance of lesions before injection in same child.

\section{REPORT OF CASES}

The following cases have been attended by me in the babies' ward of the Sydenham hospital:

CASE 1.-B. L., 6 years old, was a former patient of Dr. Tunick. The mother had an innocent infection. The boy was born with lues, affecting various parts of the body. He had a gumma of testicle for which he was castrated. At present he has a swelling of the left knee-joint, which is thicker than the right joint. The superficial veins are very prominent, and the joint is immovable; evidently gumma-periostitis. The Wassermann reaction is positive, likewise the Noguchi. I am indebted to Dr. D. M. Kaplan for the serologic examinations. An injection of 0.3 Ehrlich-Hata given in a neutral solution, in the Jeft buttock, with aseptic precautions, was not followed by local reaction. Marked benefit followed within forty-eight hours.

Repeated examinations of the urine showed no evidence of any abnormality.

TABIE 1.-EXAMINATION OF BLOOD BEFORE AND AFTER THE INJECTION (CASE 1)

$\begin{array}{ccccc}\text { Date. } & & \text { W. B. C. } & \text { Polynuc. } & \text { Lymph. } \\ 10 / 26 & \ldots \ldots \ldots & 12,200 & 80 & 20 \\ 10 / 29 & \ldots \ldots \ldots & 15,400 & 78 & 22 \\ 11 / 1 & \ldots \ldots \ldots & 16.200 & 75 & 25 \\ 11 / 5 & \ldots \ldots \ldots & 16,000 & 78 & 22\end{array}$

CASE 2.-Margaret $K$, 18 months old, a breast-fed child, was referred to my hospital service through the courtesy of Dr. Henry Whitehouse, whose diagnosis was syphilis. The child was backward in development; could not walk but could stand; said only "mamma" and "papa." Falling of hair, enlarged superficial veins of scalp, marked pallor of skin, and hemic murmur of the heart, also heard in the carotids, were present. The child had snuffles. The epitrochlear glands were easily palpable.

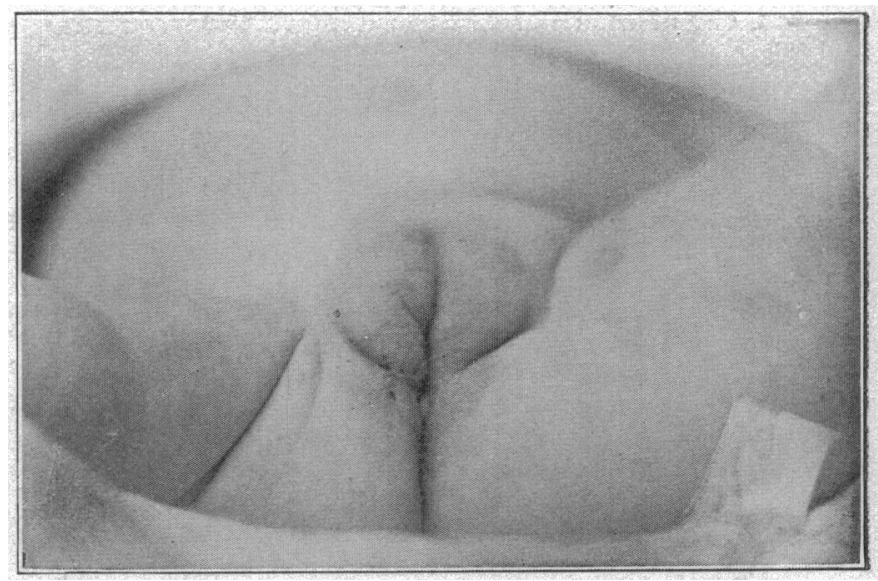

Fig. 3.-Appearance of lesions in same child one week after injection.

patellar reflex was lost, but the plantar reflex was present. The infant appeared absolutely helpless. The pulse was smalj and feeble, and the infant showed all the evidence of toxicity. We were certainly dealing with a toxic neuritis due to the injection of this remedy.

Such were the visible evidences of the toxemia. The heartsounds were feeble and muffled, and a faint murmur was heard at the apex. The child was unable to hold its head up. There was marked anorexia. Owing to the cardiac weakness I ordered

1. The Herxheimer reaction consists in an increase of any and all exanthemata after an injection of 606 , similar to mercurial treat. ment. Ehrlich believes that when this reaction occurs the parasites. instead of being lilled, are simply being trritated and produce an instrad of being killed, are simply being irritated and produce an an insufficient dose has been given. 
caffein, sodium benzoate, and hot salines to stimalate the cir culation, in addition to concentrated 'food, such as you of egg with milk, and broth, and malt soup feedings. Massage and genera1 faradization have been used almost one month with but slight improvement. "There is a slight increase in weight, due no doubt to improved metabolism. The child appears sick, is listless, and also has excessive diaphoresis. The prognosis is dubious. She is still in the hospital for further observation.

TABLE 2,-EXAMINATION OF BLOOD BEFORE AND AFTER THE INJECTION (CASE 2)

\begin{tabular}{|c|c|c|c|c|c|}
\hline $\begin{array}{l}\text { Date. } \\
10 / 18\end{array}$ & & W. C. B. & $\begin{array}{c}\text { Polynuc. } \\
73\end{array}$ & Lymph. & $\begin{array}{l}\text { Mononuc. } \\
\mathbf{3}\end{array}$ \\
\hline $10 / 20$ & $\ldots$ & 16,600 & 82 & 17 & 1 \\
\hline $10 / 22$ & $\ldots \ldots$ & 12,400 & 78 & 22 & $\because$ \\
\hline $10 / 24$ & $\ldots \ldots$ & 13,200 & 79 & 21 & $\cdots$ \\
\hline $10 / 27$ & $\ldots \ldots$ & 12,000 & 78 & 22 & \\
\hline $10 / 28$ & $\ldots \ldots$ & 12,000 & 78 & 20 & 2 \\
\hline $10 / 29$ & $\ldots \ldots$ & 12,000 & 76 & 23 & 1 \\
\hline $10 / 30$ & $\ldots \ldots$ & 12,400 & 73 & 27 & $\cdots$ \\
\hline $10 / 31$ & $\ldots \ldots$ & 12,000 & 77 & 23 & $\cdots$ \\
\hline $11 / 1$ & $\ldots \ldots$ & 12,800 & 78 & 21 & 1 \\
\hline $11 / 2$ & $\ldots \ldots$ & 12,600 & 76 & 24 & \\
\hline $11 / 4$ & $\ldots \ldots$ & 13,000 & 78 & 21 & 1 \\
\hline $1 / 5$ & $\ldots \ldots$ & 13,200 & 77 & 23 & . \\
\hline & $\ldots \ldots$ & 13,800 & & 24 & . \\
\hline & $\ldots \ldots$ & 13,600 & 77 & 22 & 1 \\
\hline
\end{tabular}

A comparison of the blood reports in Cases 1 and 2 shows a decided leukocytosis soon after the injection. This leukocytosis remained about two weeks in Case 1, until the patient was discharged.

In Case 2, still under observation, the apparent leukocytosis was soon lost, and the leukocyte count of 13,000 on admission to the hospital is now gradually reappearing. When the neuritis was at its worst the leukocyte count was at its lowest, 12,000 , and with improved nutrition the leukocytes rose as high as 13,800 . The urine showed the presence of albumin on several examinations.

CASE 3.-Helen K., 8 years old, has been under treatment for syphilis for two years. The epitrochlear and inguinal glands are swollen, the liver is very large and the spleen enlarged, extending to below the level of the umbilicus. The patient has various eruptions and nodules on tibia and radius, and cervical glands always enlarged. At present there is some icterus. The patient has been operated on for enlarged tonsils and adenoids by Dr. Freudenthal, and incised for various abscesses by myself. She has frequent ear discharge, and vaginal catarrh; has never been healthy. Wassermann and Noguchi reactions are positive. An injection of $0.3 \mathrm{gm}$. salvarsan was given in the left buttock with aseptic precaution. The condition of the child is excellent, although the liver and spleen are not noticeably reduced in size. The appetite is good.

It is four weeks since the treatment was begun in this case. There is still a local infiltration and an induration of the buttock which has not become inflamed but is still a reminder of the injection given.

In each of the three cases a single injection was given. This preliminary report is submitted as an unbiased clinical study, and the patients are still under observation. One of them, Margaret K., is still in the hospital, six weeks after the injection.

\section{CONCLUSIONS}

From a study of the foregoing experience the following deductions are justified:

First, the toxicity may be due to a hypersensitive body, possibly an idiosyncrasy.

Second, the dose of the drug $(0.3 \mathrm{gm}$. $)$ is too large for children and hereafter I shall advise no more than 0.1 of the Ehrlich-Hata preparation, the dose not to be repeated for at least several weeks, or until we are justified in assuming that there are no systemic symptoms associated with the first dose.
From my present experience I would strongly advise against the injection of ambulant patients, but would require the injection to be given either in the hospital or in a sanitarium, where proper medical supervision and competent nurses can supervise details, and note toxic symptoms as early as possible.

162 West Eighty-seventh Street.

\section{LIFE AND HEALTH AS NATIONAL ASSETS* F. F. WESBROOK, M.D. \\ Dean, College of Medicine and Surgery, University of Minnesota : Director, Laboratory Division, Minnesota State Board of Health MINNEAPOLIS}

Short-sighted humanity fails to appreciate Nature's gifts until threatened with their loss. This is true of even the greatest of her gifts, life itself. Although belated in our realization of the threatened overdraft on Nature's storehouse, a compensatory and irresistible enthusiasm has developed within the last two years which augurs well for the retention by our country of that international leadership so manifestly foreordained by Nature's bountiful equipment.

It is significant of our failure to value health, which above all other considerations makes life worth the living, that the first meeting of the governors of states failed to provide for the study of health problems. The omission was noted and in the National Conservation Commission's Report of Jan. 11, 1909, in the general schedule, special consideration was given to life and health. T'he report itself deals with five different phases of conservation, namely, minerals, lands, forests, waters, and finally, national efficiency, or health. OnIy four sections, however, were created. Health. was not provided with a special section or officers.

In the North American Conservation Congress called by. President Roosevelt Dec. 24, 1908, in addition to the conservation of the national resources already mentioned, the protection of game received attention. This was an international commission representing our own country, Canada and Mexico, which reported from Washington, Feb. 23, 1909. Among the commissioners representing the various countries there was seemingly no one whose training and paramount interest lay in the field of public health.

While it is apparent that the initial oversight has been in part repaired, it remains to be seen what progress will result from the Second National Conservation Congress, in relation to this, the people's most important natural asset.

The inclusion in the program of a paper entitled "Life and Health as National Assets" must not be taken as evidence that there is any doubt as to the real and assessable value of life and health. Rather are we called on at this time to realize that they constitute national or public resources furnished by Nature and are not to be regarded as strictly personal or private possessions. The individual life has its economic and commercial value to the community and the nation by virtue of the contribution it may be expected to make to society. This view may perhaps be novel to some. Our ideas concerning conservation of our other natural resources, however, have undergone such rapid evolution in the recent past, that we may easily orient ourselves to the

* Read before the second National Conservation Congress, St. Paul, Sept. 8, 1910 